Cad.Est.Ling., Campinas, (44):169-177, Jan./Jun. 2003

\title{
AÍ E ENTÃO EM EXPRESSÕES CRISTALIZADAS
}

\author{
MARIA LUIZA BRAGA
}

(UFRJ)

\begin{abstract}
In this article I examine the forms "ai" and "então" according to the hypothesis of "Retention of Earlier Meaning" which advocates that certain more specific semantic nuances of the source construction can be retained in certain contexts long after grammaticalization has begun (Bybee et alii 1993: 17). I show that "então" maintains the time nuance in all its uses, regardless of their stage of grammaticalization; "aï" also presents a nuance of time in its unmarked uses, which seems to contradict the abovementioned hypothesis since this form is originally an adverb of space.

The analysis of some crystalized expressions envolving "aî" shows however that the original space meaning can be retrieved in some specific contexts.
\end{abstract}

Nos estudos sobre gramaticalização, encontramos, com freqüência, discussões sobre os mecanismos propulsores desse processo bem como indagações sobre as propriedades da forma-fonte da qual derivam os itens gramaticais. A título de exemplo, consideremos as ponderações de Heine et alii (1991), por um lado, e de Bybee et alii (1993), por outro. De acordo com os primeiros:

os conceitos fonte remetem a algumas das experiências humanas mais elementares; eles são
tipicamente derivados de estado físico, comportamento ou contexto imediato do homem e
freqüentemente referem-se aos pensamentos e comunicação humana. Provavelmente fazem
parte do "alfabeto dos pensamentos humanos" e pertencem ao conjunto universal dos
primitivos semânticos (Wierzbicka 1988, 1989), independentemente da maneira como estes
sejam definidos (Heine et alii 1991:33).

Bybee et alii adotam posição semelhante e sustentam que as formas que se encontram na origem da trajetória de gramaticalização "codificam pontos de orientação primordiais na experiência humana" (1994:11). Também defendem que certas nuances semânticas mais específicas da construção fonte podem ser retidas em alguns contextos por um longo tempo após o começo do processo da mudança, o que explicaria as peculiaridades na distribuição de formas que são postas a serviço da mesma função. Ilustram esse ponto com o seguinte par de orações:

Shall I call you a cab?

Will I call you a cab?

De acordo com eles 
"Shall é mais apropriado em perguntas cujo sujeito é a $1^{\text {a }}$ pessoa porque seu sentido de obrigação implica imposição externa de deveres; conseqüentemente a pergunta pode ser construída (interpretada) como um pedido de confirmação, por parte do interlocutor, relativa à adoção, por parte do falante, de responsabilidade particular. A mesma pergunta com will soa estranha porque nuances do seu significado mais antigo, 'desejo', parecem emergir, sugerindo, de forma imprópria, que o falante está perguntando se ele/a quer chamar um taxi. O sentido de ‘desejo' (willingness) está presente, apropriadamente, quando o sujeito não é a 1 a pessoa

Will you call me a cab?

Will he call me a cab?" (1994:16)

Uma referência anterior à manutenção de aspectos do significado da forma-fonte, implícita no conceito de bleaching de Givón (1973), pode ser encontrada em Hopper (1991). Ao arrolar os princípios a partir dos quais se poderiam identificar os itens que se encontram nos estágios iniciais do processo de gramaticalização, o autor refere-se a persistência, salientando que essa manutenção pode explicar certas restrições gramaticais experimentadas pelo item em pauta em seus usos mais gramaticalizados.

A mencionada hipótese encontrou referendação no trabalho de Omena e Braga (1996) sobre a forma pronominal a gente. Em análise anterior, desenvolvida sob a ótica da metodologia da teoria da variação, Omena (1996) contrastara as formas pronominais nós / a gente e mostrara que (i) os falantes privilegiam a forma a gente, em detrimento de nós, em se tratando de referências a grupos grandes e indeterminados; (ii) havia restrições à co-ocorrência de a gente com quantificadores e numerais, como em *a gente três, restrição inoperante em se tratando de nós, como em nós três.

Omena e Braga retomam essas descobertas e explicam-nas à luz do princípio da persistência: é a preservação das nuanças do significado original do substantivo gente, coletivo de pessoa, núcleo do $\mathrm{SN}$ que funcionou como forma fonte para o processo de gramaticalização, que explica os impedimentos de co-ocorrência de a gente com numerais e quantificadores bem como a opção por esta forma em detrimento de nós, em se tratando da referenciação a grupos grandes e indeterminados nos quais se inclui o falante.

Neste artigo investigo os itens aí e então à luz da hipótese da retenção do significado original proposta por Bybee et alii (1993), lembrando que a presente análise difere da desenvolvida por Bybee et alii em três aspectos: enquanto estes focalizaram os morfemas que expressam as categorias associadas aos verbos, sob uma perspectiva diacrônica e interlingüística, circunscrevo-me a aí e então que são examinados sob um enfoque sincrônico no português falado e escrito no Brasil.

Este trabalho compreende 4 (quatro) partes: inicialmente, caracterizamos os vários usos dos elementos em estudo; na segunda parte, testo a hipótese de Bybee et alii (1993) valendo-me de dados extraídos de amostras de fala e escrita; a conclusão e as referências bibliográficas vêm a seguir, na terceira e quarta ${ }^{1}$ seções, respectivamente.

${ }^{1}$ Os dados da fala foram coletados em três bancos de dados: Amostra-80, Amostra-00 (I), Amostra-00 (C), que integram o acervo do PEUL-Projeto de Estudos sobre o Uso da Língua, sediado na UFRJ. Os dados da escrita foram extraídos, de forma mais sistemática, dos jornais impressos no Rio de Janeiro. Vali-me, de 


\section{OS VARIADOS USOS DE AÍ E ENTÃO.}

Nesta seção, atenho-me aos usos dêitico, fórico, juntivo e discursivo de aí e então.

Considerei como dêiticas/exofóricas as ocorrências similares a (1), a seguir. Neste exemplo, a identificação do referente a que remete o item em negrito requer "a referência ao falante-agora, que é o complexo modo-temporal que constitui o ponto de referência do evento de fala". (Neves 1992:264).

(1) F: E tudo que tem, algum tipo de festa, se eu num tô lá, elas ligam cá pra casa da minha mãe: “Ah, Leila tá aí?” (LEI, 04)

Quanto aos usos endofóricos, distingui as instâncias anafóricas das catafóricas, porque, em se tratando de aí, parece existir uma correlação entre tipo de remissão — anafórica vs. catafórica - por um lado, e categoria cognitiva - pessoa, objeto, espaço, tempo, "qualidade" - por outro lado. (Braga e Paiva, 2003). Exemplos para anáfora e catáfora vêm a seguir.

\section{Remissões anafóricas}

(2) F: E isso não é só na Rural não, na Fundação Getúlio Vargas, eu já vi muita coisa, mas eu trabalhei tudo quanto foi a ... Na Fundação Getúlio Vargas, aí você vê muita coisa. (DA, 42)

(3) F: Uns seis meses depois que a gente chegou, ele resolveu ir lá pedir uma vaguinha para deixar jogar. Aí desde aí ele não largou mais (GU, 62)

(4) Então, e como eu adoro italiano, a língua italiana, gostaria também de ficar um... uma temporada na Itália, porque aí eu vinha parlando italiano (HE, 34)

(5) E eu, quando estou dirigindo, ou quando estou na rua eu estou olhando para lá, estou olhando para cá. E sei que o cara entrou ali, que o outro está brigando ali, que o outro... entendeu? Então é espírito de observação, o sujeito está na rua né? está dentro de um ônibus, está num trem, está num navio, está num negócio, ele está olhando o que se passa em volta, prestando atenção na conversa o sujeito está falando, porque que está discutindo, essa coisa toda. Aí o sujeito observa mais do que os outros. (GE, 31).

$A i ́$, como os trechos acima mostram, pode recuperar constituintes diversos. Exemplos de remissão a um SPREP que expressa lugar, com referência específica, como (2) acima, são mais raros, na fala. Mais usuais são as recuperações de proposições, explícitas (3) ou inferíveis (4), e porções textuais amplas, com limites difusos, vale dizer, de delimitação problemática, como se vê em (5).

Em se tratando das remitências catafóricas, as opções se reduzem; aí é usado nãomarcadamente, em referência a constituintes que expressam a categoria espaço (6) 
(6) F: ... primeira coisa que eu acho que eu faria era abrir um asilo.

E: Asilo?!

F: Asilo que o que eu vejo de pessoas caída aí no chão. (BI, 31).

Em se tratando de então, a distinção entre empregos dêitico e fórico revela-se bastante esmaecida uma vez que a identificação do tempo físico/cronológico, vale dizer, dêitico, requer o concurso de informações temporais fornecidas textualmente, como mostram os trechos seguintes, nos quais então ora remete a um tempo passado (7), ora a um tempo futuro (8). Um exemplo mais complexo é oferecido em (9) no qual então remete a um tempo que é sequencialmente ordenado no texto, mas deiticamente recorrente.

(7) Solange Amaral emergiu com sorriso-de-espelho-meu, mas, em tempo de vampiromania, sugou o quanto pôde o sangue de Benedita, dando seqüência à tática dos últimos dias no horário gratuito. E, no momento decisivo em que Bené engrossou a voz e cobrou a recusa de César ao diálogo no 30 de setembro, fugiu, na base de bravata. Benedita, séria e prosa, leu então o artigo em que Elio Gaspari analisou a postura dos candidatos diante do toque de recolher. (O Globo, 03/10/2002).

(8) Além de conhecimento e audácia, falta-me convicção: ainda não escrevi um texto que merecesse um ponto-e-vírgula. Um dia o escreverei e então tirarei o ponto-e-vírgula do estojo com o maior cuidado e com a devida solenidade o colocarei, assim. (O Globo, 15/12/2002)

(9) O seu jantar se torna uma alegre brincadeira, reunindo toda a sua família numa descontraída aventura para ver quem vai pegar o brinde.

O bolo é servido no final da refeição sendo então repartidas as fatias, enquanto todos esperam ser contemplados. (Folheto distribuído por uma confeitaria carioca, 2003)

O fato de os trechos acima terem sido todos coletados de jornais, desnecessário lembrar, modalidade escrita, não é uma coincidência. Ocorrências similares a essa na modalidade falada, estilo casual ou semi-casual, são raras. (10), abaixo é um dos poucos exemplos de que disponho.

(10) F: Tinha um rapaz lá que era um cara muito mentiroso, então, quando lançaram a penicilina, ele... ele contando, invenção dele, né? ele contou que chegou para o médico com o vidrinho daquele falou: "Doutor, isso é penicilina, cinqüenta mil unidades." E o médico, então, disse pra ele assim: "Cinqüenta mil unidades aí?" Aí ele pegou o vidrinho, tirou a tampa, jogou o pozinho, disse... (GEO, 31$)$

No que tange a um valor anafórico, circunscrito apenas à informação textual, as ocorrências de então também são mais escassas. O trecho seguinte constitui, no entanto, um bom exemplo: nele, a conjunção alternativa $o u$ sinaliza a disjunção e o item então recupera as peças de informação apresentadas previamente.

(11) F:... a gente vê o exemplo de muitos aí, começa a estudar, mas, de repente, ele sai do colégio por quê? Há uma necessidade de sobreviver porque a gente, né? para sobreviver né? ou o camarada passa meter bronca, né? ou vai pedir esmola ou então trabalha (PC, 20) 
Os trechos que apresentei até o momento constituem instâncias mais ou menos prototípicas, que escamoteiam o fato de que as fronteiras entre dêixis e foricidade podem se tornar bastante esmaecidas. Optei, no entanto, por preservar a distinção porque aí em seu emprego como recurso dêitico se distingue de aí em remitência fóricas quanto à fronteira de constituintes. Enquanto dêitico, aí, geralmente, ocupa a posição pós-verbal; enquanto fórico ocupa a posição pré-verbal, condição necessária à sua reinterpretação como elemento juntivo. Desnecessário frisar que a correlação entre posição em fronteiras de constituintes, por um lado, e valor/uso, por outro lado, é variável.

A outra razão que me levou a priorizar um tratamento que distingue uso dêitico de uso fórico relaciona-se ao fato de aceitar que o processo de gramaticalização é gradual. Em outras palavras, os empregos anafóricos dos elementos em análise, com sua evidente imprecisão e difusão, como ilustrei previamente, parece constituir uma etapa necessária à reinterpretação do estatuto categorial de aí como elemento juntivo e discursivo.

Aí e então juntivos articulam orações enquanto aí e então discursivos colaboram na construção do tópico discursivo ou da interação. Os primeiros usos são exemplificados em (12) e (13); os segundos, em (14) e (15), a seguir ${ }^{2}$.

\section{Usos juntivos}

(12) F: Ele começou a se... a gostar de uma garota, mas a garota só dava fora nele. Aí um dia ela resolveu dizer que tinha um tal de um teste lá. Aí ele foi lá concorrer. Aí nesse teste ele consegue, ele vai trabalhar na Broadway. (GU, 62)

(13) F: Todos os meus quatro filhos são maravilhosos, mas o caçula é assim...não é por ser caçula não, é temperamento dele. Ele puxou um pouco a mãe e um pouco o pai, então temperou bem. (MG, 48)

\section{Usos discursivos}

(14) F: ... quando ele foi entrar para pista, ele bateu no poste

E: Hum

F: Mas eu não me machuquei não. E a outra vez foi... foi que eu trabalhava na kombi, essa kombi que faz frete de Santa Cruz para Antares

E: Opa! Você trabalha nisso? Você fazia o que ali, Samuel?

F: Era trocador.

E: Hum

F: Aí o motorista ia entrá pra gente chegar ali no ponto de Antares, (SAM, 01)

(15) F: ...aí o filho dele e mais uns amigos dele, só eles ali, eles consegue formar um império desgraçado contra o... o Dart. O Dart é o nome do cara do mal.

E: Como é que é?

F: O Dart é o nome do cara do mal! Então eles conseguem fazer um império desgraçado e essa guerra vira intensa. (GU, 62)

\footnotetext{
${ }^{2}$ Nessa seção, estou me restringindo àquelas ocorrências nas quais aí e então encabeçam orações que contribuem para a organização do tópico/subtópico discursivo.
} 
Uma vez caracterizados os usos de aí / então, passo a investigá-los à luz da hipótese da retenção do significado da forma fonte.

\section{A RETENÇÃO DO SIGNIFICADO DA FORMA FONTE}

Como mostrei na parte anterior, em circunstâncias não-marcadas, aí dêitico localiza uma entidade adotando o interlocutor como referência; contrapõe-se, portanto, a aqui, dêitico que sinaliza proximidade ao locutor, e a ali, dêitico que sinaliza distância dos interlocutores. Quanto ao uso anafórico, também mostrei que aí raramente remete à estrutura cognitiva espaço; em outras palavras, os falantes preferem empregar aí em remitência às categorias cognitivas tempo e qualidade.

Essa última tendência torna-se ainda mais evidente quando consideramos os chamados usos juntivos. Enquanto marca formal de conexão entre orações, aí, prototipicamente, é utilizado em contextos que implicam uma sucessão de eventos -narrações, descrições de situações dinâmicas reiterativas, instruções - ou uma continuação do texto que está sendo construído. Aqui também seu emprego aparece associado ou ao conceito tempo ou tempo / qualidade.

Quanto à função de discursivo que contribui para a organização do tópico discursivo, mostrei em trabalho anterior (2001) que os falantes cariocas estão empregando aí como elemento inicial de uma oração que retoma o subtópico, às expensas de então, mudança que parece consistente com a distribuição já apontada para os juntivos. Em outras palavras, após funcionar como item que combina orações dispostas em uma seqüência que busca reproduzir diagramaticamente a ordem dos eventos como ocorreram (teriam ocorrido) no mundo bio-físico, aí passa a funcionar em um espaço mais abstrato, o texto, contribuindo para a progressão das unidades discursivas. Aqui também, a categoria cognitiva espaço cedeu vez à categoria tempo / qualidade.

Então, por seu turno, originalmente, remete a tempo, categoria cognitiva contígua a espaço, segundo a proposta de Heine et alii (1991). Então no emprego dêiticoanafórico, mormente em SPREPs cujo núcleo é a preposição desde ou até, a primeira a indicar início e a segunda, limite, preserva a noção de tempo. Em se tratando, no entanto da recuperação do conteúdo de uma oração ou porção textual, a abrangências de então se alarga e, à semelhança de aí, passa a remeter a conteúdos proposicionais outros que não tempo.

Com relação aos usos juntivos e discursivos, então conserva as propriedades da forma fonte. Como juntivo, então tende a iniciar orações que expressam efeito, conseqüência e conclusão, as quais juntas à oração núcleo ajudam a constituir a oração complexa de causa. Como discursivo, então encabeça sequiências que (re)introduzem subtópicos ou se caracterizam como digressões, funções essas relacionadas à progressão (ou interrupção) do texto. Uma vez que a relação semântica de causa pressupõe uma ordenação dos estados-de-coisa na linha do tempo e que o texto também se constitui temporalmente pode-se afirmar que a nuance temporal persiste nesses usos. 
A análise conduzida até o momento sugere que a hipótese de Bybee et alii é confirmada a respeito de então e contrariada a propósito de aí, uma vez que os valores juntivo e discursivo da última forma não exibem aspectos relacionados a categoria cognitiva espaço. A investigação de um conjunto de construções, com variados graus de cristalização, revela, todavia, que é possível recuperar a presença de aspectos relacionados à estrutura cognitiva lugar. A título de exemplo, considerem-se (e) por aí e (es)tar aí.

Por aí aparece associado a indeterminação, incerteza; precedido por $e$ e como último item de listas, expressa continuação, como mostram (16) e (17), a seguir.

(16) E: Que que você faz?

F: Andando por aí. Andando, se divertindo um bocado. (CA, 18)

(17) A Luana Piovani é mesmo uma sortuda: na sua coleção de gostosos estão Marcos Palmeiras, Rodrigo Santoro, Cristiano Rangel, Caco Ricci ("um Deus"), Paulinho Vilhena (Projeto Vale Tudo) e por aí vai. (O Globo 09/02/03)

Além da preposição por, morfema que já em sua origem latina traz inscrita a referência a lugar (Nascentes 1952, Mattos e Silva 1989, Poggio 2002), vale lembrar que por aí tende a coocorrer com verbos de movimento; e por aí, por sua vez, tende a ser acompanhado por adverbiais relacionados a lugar. Em outras palavras, a investigação do co-texto em que por aí é usado revela que os traços de significado da forma-fonte não foram completamente descartados.

Já o significado da outra construção, (es)tar + aí, encontra-se atrelado à polaridade: se positiva, introduz um argumento favorável, relevante à hipótese que o falante / escritor vinha desenvolvendo, como se pode observar em (18); se negativa, sinaliza descomprometimento com referência a fatos introduzidos previamente, como ilustra (19).

(18) E também podemos ficar sossegados quanto ao patrimônio do povo fluminense e carioca (sim, "fluminense" devia abranger "carioca", mas todo mundo sabe que fluminense é uma coisa e carioca é outra, estão aí mesmo os resultados das eleições, que não me deixam mentir)...(O Globo, 05/01/2003)

(19) Vai conquistar quem nunca se deixou convencer nesses 20 anos? Não. Vai bater recordes de bilheteria? Não mesmo (a julgar pelas estimativas de mercado, será o primeiro filme de "Guerra nas Estrelas" a não fechar o ano no topo da lista de campeões de público". Mas os fãs não estão nem aí e estão certos: "Star Wars - episódio 2: Ataque dos clones", que chega hoje aos cinamas do Rio, foi feito para eles. (O Globo 07/2002)

Em paralelo ao uso argumentativo de (es)tar aí, existe um outro em que aí funciona como dêitico que aponta para uma entidade facilmente identificável em um espaço físico próximo, como ilustra (20), extraído de seção que se encontrava contígua a uma foto.

(20) ANO NOVO, governo novo, o poder de cara nova. Aí estão as new faces da Era Lula (O Globo 04/01/2003) 
O que a análise de (e) por aí e (es)tar aí mostra, então, é que uma mesma construção, em uma mesma sincronia, pode se dispersar em valores diferenciados nos quais é possível discernir nuances relacionadas à estrutura cognitiva da forma-fonte.

\section{CONCLUSÃO}

Neste trabalho investiguei os itens aí e então à luz da hipótese de Bybe et alii, segundo a qual certas nuances semânticas mais específicas de construções que funcionam como fonte de uma trajetória de gramaticalização podem ser preservadas em alguns contextos por um longo tempo após o início do processo de mudança.

Para tanto, considerei as formas em tela segundo seus valores dêitico-fórico, juntivo e discursivo, salientando as diferenças entre aí e então no que concerne à hipótese que me guiou. $\mathrm{O}$ exame das ocorrências de então mostra que é possível detectar traços relacionados à categoria cognitiva tempo, qualquer que seja o uso; o estudo de aí desvenda um quadro mais complexo já que seus usos como juntivo e discursivo prescindem do traço relacionado a espaço. Mostrei, porém, que esse mesmo traço pode ser identificado em expressões mais ou menos cristalizadas, comprovandose, assim, a hipótese levantada por Bybee et alii.

\section{REFERÊNCIAS BIBLIOGRÁFICAS}

BRAGA, M.L. (2001). Aí e então e a hipótese da trajetória universal. In NEVES, M.H.M. (Org.) Descrição do português: definindo rumos de pesquisa. Araraquara, Cultura Acadêmica Editora.

BRAGA, M.L. \& PAIVA, M.C. Do advérbio ao clítico é isso aí. In RONCARATI, C.N. (Org.) Português brasileiro: contato lingüístico, heterogeneidade e história. No prelo.

BYBEE, J.; PERKINS, R. \& PAGLIUCA, W. (1994). The evolution of grammar. Tense, aspect and modality in the languages of the world. Chicago and London, The University of Chicago Press.

GIVÓN, T. (1993). The time-axis phenomenon. Language 49. p.890-925.

HEINE, B.; CLAUDI, U. \& HÜNNEMEYER, F. (1991). Grammaticalization. A conceptual framework. Chicago and London, The University of Chicago Press.

HOPPER, P.J. (1991). On some principles of grammaticalization. In TRAUGOTT, E.C. \& HEINE, B. (Eds.) Approaches to grammaticalization. Philadelphia, John Benjamins Company, v.i, p.17-35.

MATTOS E SILVA, R.V. (1989). Estruturas trecentistas: elementos para uma gramática do português arcaico. Lisboa, Imprensa Nacional/Casa da Moeda, $870 \mathrm{p}$.

NASCENTES, A.V. (1952, 2v). Dicionário etimológico da língua portuguesa. Rio de Janeiro, Francisco Alves.

NEVES, M.H.M. (1992). Os advérbios circunstanciais de lugar e tempo. In ILARI, R. (Org.) Gramática do português falado. Níveis de análise lingüística. Campinas, Editora da Universidade Estadual de Campinas. V. ii, p.261-296. 
OMENA, N.P. (1996). A referência à primeira pessoa do discurso no plural. In OLIVEIRA e SILVA, G.M. \& SCHERRE, M.M.P. (Orgs.) Padrões Sociolingüísticos. Análise de fenômenos variáveis do português falado na cidade do Rio de Janeiro. Rio de Janeiro, Tempo Brasileiro, p.183-215.

OMENA, N.P. \& BRAGA, M.L. (1996). A gente está se gramaticalizando? In MACEDO, A.T.; RONCARATI, C.N. \& MOLLICA, M.C. (Orgs.) Variação e discurso. Rio de Janeiro, Tempo Brasileiro, p. 75-83

WIERZBICKA, A. The alfabet of human thoughts. Linguistic Agency, University of Duisburg, ser. A, vol. 245. Duisburg: Universität Duisburg Gesamthochschule. Apud HEINE, B.; CLAUDI, U. \& HÜNNEMEYER, F. (1991). Grammaticalization. A conceptual framework. Chicago and London, The University of Chicago Press. 